\title{
Comparison of Static Effect of Vehicle Load between China and America
}

\author{
You Weijie ${ }^{[1]}$, Wang Youzhi ${ }^{[1]}$, Wang Shimin ${ }^{[1]}$, Zhang Tao ${ }^{[2]}$, Zhang xue ${ }^{[1]}$, Yuan \\ Quan $^{[1]}$, Xu Gangnian ${ }^{[1]}$, An $\operatorname{Ran}^{[1]}$
}

(1、School of Civil Engineering, Shandong University, Jinnan, China

2. SHANDONG LUQIAO GROUP Limited Liability company, Jinnan, China)

Keywords: Comparison, Static Effect, Vehicle load, China, AMerica.

\begin{abstract}
According to the bridge specifications on vehicle loads in China and the United States, this paper analyzes the influence of vehicle loads on static characteristics of bridges between the two countries' bridge specifications by finite element simulation, and reveals the differences of vehicle loads in bridge specifications and its influence on the internal force between the two countries.

AASHTO LRFD Bridge Design Specification, developed by American Association of State Highway and Transportation Officials (AASHTO), is a bridge design specification which is widely used in the world. Bridge specification comparison of China and the United States is particularly important for foreign projects, which can help Construction personnel and researchers overseas better understand the differences of two specifications, thus to further improve Chinese bridge specification. Automobile load is an important part of bridge design. Liu ${ }^{[1]}$ has studied and compared the history and present situation of AASHTO LRDF bridge specification in the United States with china's, and introduced the development history and theoretical background of American code. WANG ${ }^{[2]}$ introduces the AASHTO LRFD design method of internal force and rate, flexural bearing capacity calculation results, and a rectangular beam example is calculated and compared which concluded that the United States code tends to have more ductility in bridge design and pay more attention to components of damage when calculate formula, and compares two sets of specifications for a certain amount of research. The bearing capacity of the calculated results show that the bearing capacity of two codes are basic same, but AASHTO LRFD combination of internal force is larger influenced by the load, the material, the transverse distribution coefficient, load effect subentry coefficient and calculation formula. In conclusion, there are few studies on the static effect of automobile load of two specifications. This paper is of practical significance for the comparison and research of automobile load differences between Chinese bridge specifications and the United States's.
\end{abstract}

\section{Comparison of vehicle load}

\section{1 comparison of Layout}

The American bridge specifications ${ }^{[3]}$ stipulates that the automobile live load on the deck or attached structure shall be the hl-93, which shall include the following two combinations:

(1) The design truck and the design tandem, its longitudinal and horizontal layout is as follows :

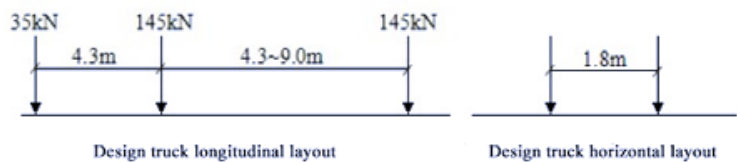

Fig.1 Characteristics of the Design truck in AASHTO specifications

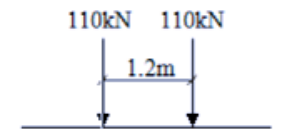

Design of two-axis longitudinal layout

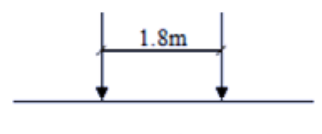

Design of two-axe horizontal layout

Fig.2 Characteristics of the Design tandem in AASHTO specifications 
(2) Design lane load, its longitudinal layout is as follows:

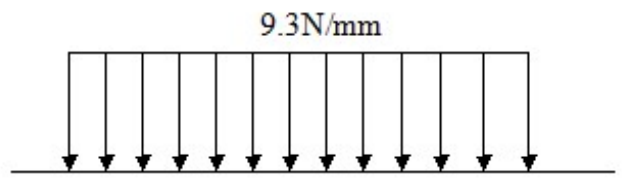

Fig.3 Uniform load in AASHTO specifications

China bridge specification[4] the motor load is divided into highway I and highway II two grades。Which concludes lane load and vehicle load。

The lane load is composed of uniformly distributed load and concentrated load. The layout is as follows :

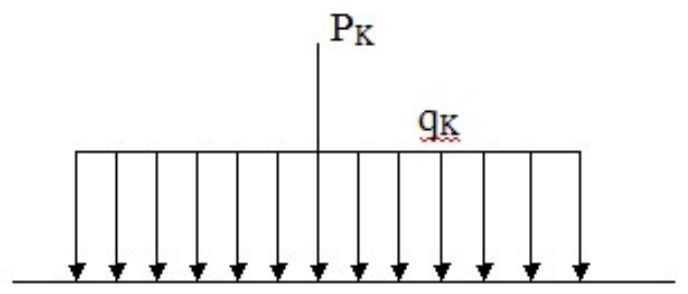

Fig.4 Lane load in Chinese code

The vehicle load layout is as follows :

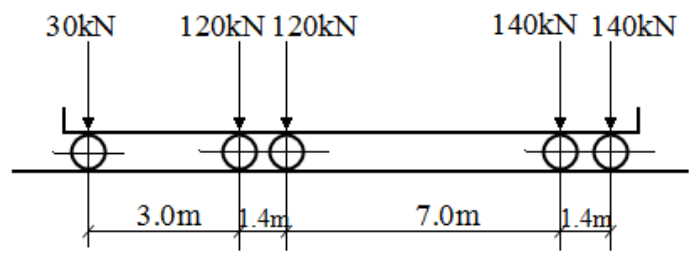

Fig.5 Vehicle load elevation layout in Chinese code

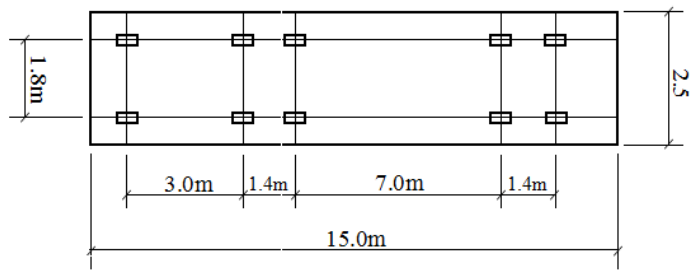

Fig.6 Vehicle load plane layout in Chinese code

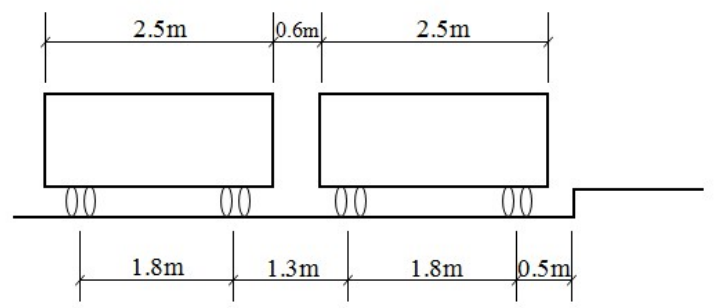

Fig.7 Vehicle load horizontal layout in Chinese code

The lane load is only a uniformly distributed load in United States's specifications, and it includes a uniformly distributed load and a concentrated load in the Chinese code. The lane load values in American bridge code size between China highway I level and II level in bridge, and the concentrated load is changed based on bridge span. The Chinese bridge regulation stipulates that the land load is used for the calculate of the most conditions of the bridge, while the vehicle load is mainly used for the calculation of the local loading, culvert, bridge and retaining wall pressure of the bridge structure. The United States bridge regulation provides that vehicle loads and lane loads can be superimposed on the deck and the maximum loading effect is the maximum of the following 
conditions : (1)The effect of the design tandem combined with the effect of the design lane load; (2) The effect of one design truck with the variable axle spacing specified in Article 3.6.1.2.2, combined with the effect of the design lane load; (3)For both negative moment between points of contraflexure under a uniform load on all spans, and reaction at interior piers only, 90 percent of the effect of two design trucks spaced a minimum of $15000 \mathrm{~mm}$ between the lead axle of one truck and the rear axle of the other truck, combined with 90 percent of the effect of the design lane load. The distance between the 14500-N axles of each truck shall be taken as $4300 \mathrm{~mm}$.

\subsection{Comparison of vehicle load value}

Table.1 Comparison of Vehicle load

\begin{tabular}{|c|c|c|c|c|}
\hline \multirow{2}{*}{ Type } & \multirow{2}{*}{ Unit } & \multicolumn{2}{|c|}{ American code } & \multirow{2}{*}{ Chinses code } \\
\cline { 3 - 4 } & & Truck & tandem & \\
\hline Vehicle gravity standard value & $\mathrm{kN}$ & 325 & 220 & 550 \\
\hline $\begin{array}{c}\text { Front axle gravity standard } \\
\text { value }\end{array}$ & $\mathrm{kN}$ & 35 & 110 & 30 \\
\hline Axial gravity standard value & $\mathrm{kN}$ & 145 & - & $2 \times 120$ \\
\hline Rear axle gravity standard value & $\mathrm{kN}$ & 145 & 110 & $2 \times 140$ \\
\hline wheelbase & $\mathrm{m}$ & $4.3+4$. & 1.2 & $3+1.4+7+1.4$ \\
\hline tread & $\mathrm{m}$ & 1.8 & 1.8 & 1.8 \\
\hline $\begin{array}{c}\text { Front wheel landing width and } \\
\text { length }\end{array}$ & $\mathrm{m}$ & $0.51 \times 0.25$ & $0.51 \times 0.25$ & $0.3 \times 0.2$ \\
\hline $\begin{array}{c}\text { Middle, rear wheel landing } \\
\text { width and length }\end{array}$ & $\mathrm{m}$ & $0.51 \times 0.25$ & $0.51 \times 0.25$ & $0.6 \times 0.2$ \\
\hline Vehicle dimensions & $\mathrm{m}$ & - & - & $15 \times 2.5$ \\
\hline
\end{tabular}

It can be seen from the table that the vehicle gravity in the Chinese bridge specification is larger than the vehicle gravity in the American bridge code. The front axle is Basically the same, and the middle axis and the rear axle are different; Wheelbase is a fixed value in the Chinese bridge code, the bridge of the truck wheelbase is more agile in the American's which the axis and the rear axle are between between $4.3 \sim 9 \mathrm{~m}$ and it's convenient to adjust when loading in order to achieve the most unfavorable condition; The wheelbase of Chinese and American norms are the same; The surface area of the tire in the American bridge specification is larger than that of the Chinese bridge code, and the regulation of the American bridge is more detailed on the floor area of the tyre. The size of the vehicle is not specify in American's code, and the size of some vehicles is special which may affect the actual situation.

\subsection{Comparison of vehicle load transverse distribution coefficient}

The stipulation of uniform load transverse distribution design in AASHTO specifications ${ }^{[3]}$ is: In the transverse, it should be assumed that the design uniform load is uniform in the $3000 \mathrm{~mm}$ width, and the force effect caused by the design uniform load should not be affected by the Dynamic load increment.

The numerical value of the transverse distribution coefficient in two countries' specifications ${ }^{[3][4]}$ is as follows: 
Table.2 Comparison of Multiple Presence Factors

\begin{tabular}{|c|c|c|c|}
\hline \multicolumn{2}{|c|}{ Chinese code } & \multicolumn{2}{c|}{ AASHTO specifications } \\
\hline $\begin{array}{c}\text { reduction } \\
\text { factor }\end{array}$ & $\begin{array}{c}\text { reduction } \\
\text { factor }\end{array}$ & $\begin{array}{c}\text { reduction } \\
\text { factor }\end{array}$ & $\begin{array}{c}\text { reduction } \\
\text { factor }\end{array}$ \\
\hline 1 & -- & 1 & 1.20 \\
\hline 2 & 1.00 & 2 & 1.00 \\
\hline 3 & 0.78 & 3 & 0.85 \\
\hline 4 & 0.67 & & \\
\hline 5 & 0.60 & \multirow{2}{*}{$>0.65$} \\
\hline 6 & 0.55 & & \\
\hline 7 & 0.52 & & \\
\hline 8 & 0.50 & & \\
\hline
\end{tabular}

It can be seen from the table above that the multi-lane transverse reduction factors in Chinese codeare more elaborate, the reduction factors in AASHTO specifications are unified into 0.65 when the number of lanes is bigger than 3, the reduction factors in Chinese code are less than that in AASHTO specifications when the number of lanes is bigger than 5, which means the design in AASHTO specifications is more conservative; When there is only one lane, the reduction factor in AASHTO specifications is 1.2, which amplify the vehicle load actually. In AASHTO specifications, the one lane reduction factor is determined by statistical test data of the action of two cars at the same time, the action effect of one car on the bridge could be more negative than that of two cars, but there is no similar stipulation in Chinese code.

\section{Finite element analysis}

Based on a two-span continuous beam finite element model, the actual bridge calculation influence caused by the differences of vehicle load in Chinese code and that in AASHTO specifications are illustrated. In order to better illustrate the differences in the design and calculation of prestressed concrete bridges between China and the United States, a two-span continuous beam finite element model is built in this chapter, and it is calculated according to Chinese code and AASHTO specifications respectively.

\subsection{Overview of the mode}

Material parameters and related parameters

Table.3 Material

\begin{tabular}{|c|c|c|c|c|}
\hline $\begin{array}{c}\text { specific } \\
\text { ation }\end{array}$ & \multicolumn{2}{|c|}{ AASHTO specifications } & \multicolumn{2}{c|}{ Chinese code } \\
\hline project & strength grade & $\begin{array}{c}\text { elasticity } \\
\text { modulus }\end{array}$ & strength grade & $\begin{array}{c}\text { elasticity } \\
\text { modulus }\end{array}$ \\
\hline concrete & $f_{c}^{\prime}=4000 \mathrm{psi}$ & $3.03 \mathrm{E} 10 \mathrm{~Pa}$ & $f_{c}=27.6 \mathrm{MPa}$ & $3.13 \mathrm{E} 10 \mathrm{~Pa}$ \\
\hline $\begin{array}{c}\text { steel } \\
\text { strand }\end{array}$ & $f_{p u}=1860 \mathrm{MPa}$ & $1.97 \mathrm{E} 11 \mathrm{~Pa}$ & $f_{p k}=1860 \mathrm{MPa}$ & $1.95 \mathrm{E} 11 \mathrm{~Pa}$ \\
\hline
\end{tabular}

The bridge is a prestressed concrete box girder bridge, it has a total of 2 spans, the length of each span is $80 \mathrm{ft}(24.38 \mathrm{~m})$ and the total length is $160 \mathrm{ft}(48.77 \mathrm{~m})$, the bridge is designed with straight line. The bridge adopts three-chamber single box girder, as shown in fig.6.1, and has a total width of $34 \mathrm{ft}$ $(10.36 \mathrm{~m})$, the height of terminal is $5 \mathrm{ft}(1.52 \mathrm{~m})$ and the pier top section is $9 \mathrm{ft}(2.74 \mathrm{~m})$, the change of the height follows second degree parabola. Three cylindrical piers ,are used in the bridge , the pier diameter is $5 \mathrm{ft}(1.52 \mathrm{~m})$ and pier height is $28 \mathrm{ft}(8.53 \mathrm{~m})$. The total bridge has 2 lanes, with a width of $14 \mathrm{ft}(4.27 \mathrm{~m})$ per lane. 


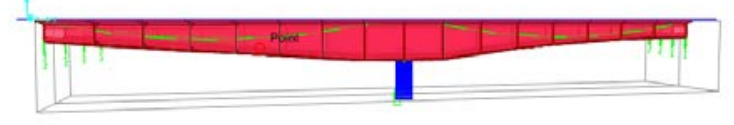

Fig.8 Model elevation

\subsection{The design and combination of load}

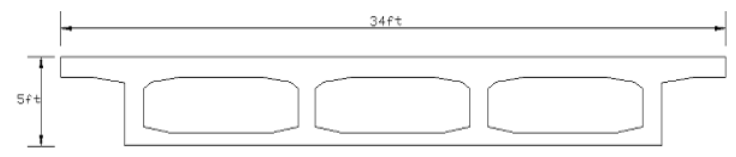

Fig.9 Section

Compare the internal forces caused by American HL-93M tandem load and HSn-4 trunk load with that caused by highway class I and highway class II in Chinese code, analyze the moment and shear force load effect of midspan(12.19m) and top of pier(24.38m).

\section{Calculation result and analysis}

Comparison between design truck and design tandem load effect in AASHTO specifications:

Table.4 Internal force at the key sections

\begin{tabular}{|c|c|c|c|c|c|c|c|}
\hline $\begin{array}{l}\text { load } \\
\text { effect }\end{array}$ & $\begin{array}{c}\text { sectio } \\
\mathrm{n}\end{array}$ & $\begin{array}{l}\text { positio } \\
\mathrm{n}(\mathrm{m})\end{array}$ & $\begin{array}{c}\text { value } \\
\text { relations } \\
\text { hip }\end{array}$ & $\begin{array}{l}\text { highway } \\
\text { class I }\end{array}$ & $\begin{array}{l}\text { design } \\
\text { tandem }\end{array}$ & $\begin{array}{l}\text { highway } \\
\text { class II }\end{array}$ & design truck \\
\hline \multirow{4}{*}{$\begin{array}{l}\text { M3 } \\
(\mathrm{kN} \cdot \\
\mathrm{m})\end{array}$} & mids & \multirow{2}{*}{12.192} & Max & 4572.44 & 3706.79 & 3429.33 & 2396.09 \\
\hline & pan & & Min & -1828.86 & -1496.61 & -1371.65 & -1015.58 \\
\hline & top of & \multirow{2}{*}{24.38} & Max & 244.36 & 90.71 & 183.28 & 59.35 \\
\hline & pier & & Min & -6500.40 & -3673.60 & -4875.30 & -1972.77 \\
\hline \multirow{4}{*}{$\begin{array}{c}\mathrm{V} 2 \\
(\mathrm{kN})\end{array}$} & mids & \multirow{2}{*}{12.19} & Max & 597.71 & 402.94 & 448.28 & 256.77 \\
\hline & pan & & Min & -399.22 & -257.89 & -299.42 & -178.10 \\
\hline & \multirow{2}{*}{$\begin{array}{l}\text { top of } \\
\text { pier }\end{array}$} & \multirow{2}{*}{24.38} & Max & 1172.54 & 844.55 & 879.40 & 558.35 \\
\hline & & & Min & -3.34 & -0.29 & -2.50 & -0.27 \\
\hline
\end{tabular}

Based on the approximate relationship of internal forces under four kinds of loads, the upper table is arranged from large to small, including the bending moments and shear values of the midspan and the top of piers.

It can be seen from the table above that the internal force of beam caused by design tandem is significantly higher than that caused by design trunk, the internal force caused by design trunk is about $75 \%$ of that caused by design tandem, which is consistent with Chinese code, in Chinese code, the internal force caused by highway class II uniform load is about $75 \%$ of that caused by highway class II uniform load.

It can also be seen from the table above that internal forces caused by highway class I vehicle load and highway class II vehicle load in Chinese code are larger than that caused by design tandem and trunk, the highest load effect of American car load is design tandem, the internal force caused by it is about $80 \%$ of that caused by Chinese highway class I; The load effect of highway class II in Chinese code is higher than that of design trunk in AASHTO specifications, the internal force midspan caused by design trunk in AASHTO specifications is about $70 \%$ of that caused by highway class II in Chinese code, only the mid-span moment is lower than that in AASHTO specifications.

\section{Conclusion}

The method of finite element simulation is used to compare the specification of Bridges of China with the United States's about the car load part , and conclusions are drawn:

(1)The vehicle load elevation layout in AASHTO specifications is quite different from that in Chinese code, and the vehicle load and uniform load in AASHTO specifications can be used in 
conjunction with each other during calculation, while the vehicle load in Chinese code can is only for local calculus; The vehicle load value and wheelbase layout in AASHTO specifications are not quite different from that in Chinese code; The transverse distribution coefficient in AASHTO specifications is more detailed than that in Chinese code.

(2) It can be seen from the finite element simulation result that the internal forces caused by highway class I vehicle load and highway class II vehicle load in Chinese code are respectively larger than that caused by design tandem and design train and car load, the former values are $70 \%-80 \%$ that of the latter.

\section{References}

[1]LIU Jian. AASHTO LRFD bridge design specification history and current situation[J]. Journal of Highway and TransportationResearch and Development(Application technology), 2010, (11) : 406-410.

[2] WANG Xiang-yang, JI Shao-bo, SHI Ming-qiang. Comparison and Study of internal Force Calculations in Chinese and American Bridge Design Specifications[J]. World Bridges, 2007, (4): 78-78.

[3]AASHTO. AASHTO LRFD Bridge Design Specification[S],2007.

[4] Industry standards of the People's Republic of China. General specification for highway bridge design(JTG D60-2015)[S]. Beijing: China Communications Press. 